\title{
Towards Critical Thinking and Its Perception in Georgia (Tbilisi Open Teaching University
} Case)

\author{
Sophia Moralishvili \\ Professor, Tbilisi Open Teaching University \\ Khatia Shevardnadze \\ Professor, Tbilisi Open Teaching University \\ Rusudan Tkeshelashvili \\ Professor, Tbilisi Open Teaching University
}

\begin{abstract}
Critical thinking, as the highest expression of thought, has become a subject of major concern in recent years in the Georgian educational field. Although advanced technologies are replacing humans in many spheres of life, people still possess the skills which can never be substituted by machines. One such skill is critical thinking. Therefore, the main purpose of education is to develop and advance this ability. Within the frames of the presented study, we aimed to investigate students' perception of their critical thinking at Tbilisi Open Teaching University. We also aimed to determine if students saw the necessity of mastering critical thinking skills and which teaching methods they considered as more effective. Up to 500 undergraduate and postgraduate students completed the survey. Findings indicate that students perceive critical thinking skills as the most significant and essential component in their education, but see different barriers while acquiring them. It is also noteworthy to note that students' awareness of critical thinking skills and methods has considerably increased recently.
\end{abstract}

Keywords: critical thinking, bachelor students, master students, teaching methods

\section{Introduction}

It is an axiom that thinking is a rule of human cognitive activity and a vital need. It is related to the needs of independence and freedom, creativity and personality.

People constantly try to expand the area of thinking, but this does not mean an increase in the quantity of knowledge. The literacy level is not limited to the number of books read. We are all well aware of the fact that technologies are changing rapidly and are becoming more and more sophisticated; state of the art technology is introduced to us every day. In all spheres of life, a storm of information is overwhelming which does not simplify our thought, but on the contrary, makes it more complicated and often obscure.

For the 21st century people, it is not essential to know much about the different fields of science and culture, but we should be able to analyze any situation, process information, understand and make choice in the fastest changing environment. The choice often involves making a hard decision, which will necessarily result in the conflict of values. Therefore, we must be prepared to face these challenges when we have to make a correlation between material-success oriented actions, personal freedom and mutual-understanding oriented actions.

Diane F. Halpern an American psychologist and former president of the American Psychological Association says that most people finish official education from ages 18 to 22. "Let us assume that the average life expectancy of today's youth is the greatest in human history, most of them will probably live more than 70 years. It is difficult to imagine what the reality will be in 2080-2090. One we can say with certainty: Most of those who are young today will have to perform the work and use technologies that do not even make sense to modern science fiction. Thus, what kind of knowledge do you need in the first stage of life to feel calm for the next 50 years?" 
As the world is entering the new phase of civilization educators need to take into account new paradigms. Alex Gray, in his article "The 10 skills you need to thrive in the Fourth Industrial Revolution" states: "Five years from now, over one-third of skills $(35 \%)$ that are considered important in today's workforce will have changed. By 2020 , the Fourth Industrial Revolution will have brought us advanced robotics and autonomous transport, artificial intelligence and machine learning, advanced materials, biotechnology and genomics. These developments will transform the way we live, and the way we work." 1 . As the World Economic Forum survey suggests critical thinking will become one of the top three skills workers will need in near futures.

The scientists agree that the solution is in the perspective education which should be the basis of the two principles: 1 . Ability to orientate swiftly in the vast information flow and to find the necessary material; 2 . Ability to understand correctly and apply received information. First, it is necessary to sift the information, to organize it, to distinguish between secondary and main information, to analyze, interpret and accept. If we do not have the ability to look into the diversity of issues, then we may find answers to questions, but we can not reflect them.

Thus, critical thinking involves analyzing ideas in a skillful way and then applying them in a useful one. To do this well, a person needs to be able to observe, reflect, synthesize, and imagine concepts and information and to communicate the results. In short, critical thinking is the desired end product of much of what we do in education.

Joseph Aoun states in his article "Machines are getting better at many of the elements that fall under the umbrella of critical thinking, including observation and communication. But they have not grasped all of them. Thus, when a lawyer mulls a thorny contract dispute and figures out how to position a client for a victory and when a marketer crafts the content of a website that keeps eyes on the screen, they are using cognitive capacities that are exclusively human. Critical thinking will therefore remain a cornerstone of human work in the digital age." 2

\section{Educational Policy Framework in Georgia}

Heated debates on the issues of education and thinking are taking place around the world. Critical thinking is one of the main directions of education in the modern world. It also defines the education policy in Georgia, which aims not only to study and memorize the collected and analyzed data, but also to develop independent thinking skills which is a sign of personal development. That is the continuous process of life.

In this regard, it is interesting to note that the important initiatives have been recently announced by the Minister of Science, Culture and Sport, Mikheil Batiashvili. ${ }^{3}$ The new reform concerns pre-school education, secondary education, vocational education, higher education and science. He noted that today's model is mainly based on remembering something and then conveying its meaning. In other words, how much information we can remember and render. Nowadays we have quite new challenges and approaches towards learning. The example of the Finnish schools and other successful educational systems prove that the main focus should be on the child's thinking and developing these skills. Of course, knowledge is an important component, but with knowledge it is important to develop thinking, discussion, problem solving and other creative and critical skills which will guarantee their success in the modern world. Accordingly, the model implies a significant update.

It can be said that any change to the education system, requires time, persistence and learning from mistakes.

We agree with the Minister of Education and would like to add that such changes could be implemented at any stage of life and at any age. To accomplish this goal the suitable curriculum and appropriate teaching are essential. Unfortunately, we can not agree with those who think that the critical thinking should be thought only at the higher educational institutions and not at the school level. We assume this to be the wrong and harmful assumption and consider intellectual autonomy to be not only teachers' priority but the pupils' as well.

\footnotetext{
${ }^{1} \mathrm{https} / /$ www.weforum.org/agenda/2016/01/the-10-skills-you-need-to-thrive-in-the-fourth-industrial-revolution/

$2 \mathrm{https} / / /$ medium.com/cxo-magazine/in-an-age-of-machines-critical-thinking-gives-people-the-edge-e2b80d0ff439

$3 \mathrm{https} / / /$ mes.gov.ge/content.php?id=8926\&lang=eng
} 
At Tbilisi Open University we see things not as they are, but as they could be. Established in 2002, Tbilisi Open University (TOU) is highly ranked institution offering bachelors, masters and one-step medical programs through its four schools and multiple degree courses. ${ }^{1}$

The aim of the university is to equip students with the practical, intellectual, creative and critical skills that are in accordance with the latest trends of the international labor market by providing newest teaching methodologies, favorable research conditions and assistance in development of practical skills. We try to accomplish these goals through the innovative curriculum and courses.

Our survey perused an objective to investigate students' perception of their critical thinking at Tbilisi Open Teaching University. We also aimed to determine if students saw the necessity of mastering critical thinking skills and which teaching methods they considered as more effective.

\section{What is Critical Thinking?}

It is impossible to answer this question within the frames of the given article. Though it is obvious that critical thinking is a skill, which is as important as speaking, reading, listening, writing, arithmetic and the development of these basic skills need to be given the profound attention. Without critical thinking, it is almost impossible to perform any work. It allows people to realize their own self and contribute to the development of a better society.

David Klooster's (2000) defines five arguments of critical thinking. The very first part of his broad definition highlights the fact that critical thinking is an independent thinking. What it means is that each student has to think for himself / herself; students have to be capable of self-contained opinions and convictions. Attention should be paid not to make the mistake of understanding this independent thinking as something necessarily original. A critical thinker does not always have to be original; there is obviously the possibility of coming to the same conclusions as others, but even in such a situation there is still an inner relationship between the student's values, opinions, convictions, and the thought.

The second component of critical thinking discussed by Klooster (2000) is the importance of seeing information as a starting point, not as a goal of education. Before students can reach the point of applying critical thinking, they need to gain quite a voluminous amount of information. In other words, application of critical thinking must be established on good knowledge of a particular issue, possibly facts conveyed by teachers.

The third aspect of the definition of critical thinking is problem solving. A human being is naturally curious, but as many other experts on education, Klooster also briefly comments on the fact that that the older the students are the lower is their curiosity. Similarly Lipman (2003) mentions this decline in correspondence with Klooster. Lipman (2003) discusses possible reasons for this decline of students' activity and interest during their school years and as a major factor of this decline he considers the school environment, which he describes as uniformed, uninspiring and often not thought-provoking. One way of improving this unfavourable situation is making the teaching process more personal for the students. It is the teachers' role then to try to encourage students to take interest in things and problems around them, because only when students see a personal profit and practical application of the topic, then they are really learning and thinking. Problem solving supports critical thinking once students are really engrossed in the problem, when they need to think of various factors, conditions, and points of view.

The forth part of Klooster's definition considers arguments. Critical thinking involves approaching a question, a problem or an issue from various angles. As there is not a singular solution to a problem, critical thinkers use arguments to support their opinion. An argument then consists of three parts. The first one is an assertion; this is the base for the argument. Arguments are supported by reasons, and reasons are supported by proofs, for example reference to particular places of a text. Critical thinker is supposed to accept that there are other possible approaches towards a given problem which he I she can either adopt or disprove. Such decision making is seen as a core definition of critical thinking by many authors; thinking about the world around us and drawing our own conclusions instead of accepting them blindly.

\footnotetext{
1 https://old.tou.edu.ge/lang/en
} 
The fifth approach speaks about a relationship between critical thinking and thinking in society. In the process of reaching perfection in our thoughts we need opinions and ideas of other people. Exchanging arguments, reading, or debating is what improves our thoughts and thinking abilities (Klooster, 2000).

Brookfield (2012) describes critical thinking as a process composed of four stages. The first stage is called "hunting assumptions." Assumptions are principles, often adopted uncritically, on which we base our judgements and actions. In critical thinking it is essential to realize what the particular assumptions influencing our actions are. Once we are aware of them, it is time to evaluate their relevance and accuracy. Instead of simply accepting unthinkingly the assumption, a critical thinker considers the evidence for the assumption. It may be something we have experienced, or something which is presented to us by trustworthy authorities, or something on which we performed our own research. The third step of the critical thinking process is about problem solving; looking at things from different points of view. Applying different viewpoints helps us to realize whether the assumption we hold is or is not relevant and appropriate considering a particular situation. All the steps described above: hunting assumptions, checking assumptions, and looking at things from different viewpoints lead to the main objective of critical thinking "taking informed actions". From what has been written above, it can be said that informed action is not just an action performed based on our feelings or unsupported evidence, but on the contrary, it is and action based on reliable evidence, evidence which when questioned by others we are able to justify and give good reasons for.

John Dewey, an outstanding representative of critical thinking movement, defines critical thinking as "Active, persistent, and careful consideration of a belief or supposed form of knowledge in the light of the grounds which support it and the further conclusions to which it tends" (Dewey, 1909).

Robert Ennis defines critical thinking as reasonable and reflective thinking focused on deciding what to believe or do. "This definition I believe captures the core of the way the term is used in the critical thinking movement. In deciding what to believe or do, one is helped by the employment of a set of critical thinking dispositions and abilities that I shall outline. These can serve as a set of comprehensive goals for a critical thinking curriculum and its assessment. Usefulness in curriculum decisions, teaching, and assessment, not elegance or mutual exclusiveness, is the purpose of this outline. For the sake of brevity, clarification in the form of examples, qualifications, and more detail, including more criteria, are omitted, but can be found in sources listed below, but most fully in my Critical Thinking (1997)". ${ }^{1}$

Paul believes that, because critical thinking allows us to overcome the sway of our egocentric and sociocentric beliefs, it is "essential to our role as moral agents and as potential shapers of our own nature and destiny"(Paul 1990).

Kuhn (1999) declared that critical thinking is directly related to metacognitive competencies or higher-order thinking skills which help the individuals to know about their knowing and that of others which is in contrast to lower order thinking. Kuhn's meta-knowing entails metastrategic skills which are closely related to the procedural knowledge, metacognitive which is closely associated with the declarative knowledge and epistemological which is related to the broader understanding of knowledge.

\section{Research Methodology}

The research was carried out using qualitative and quantitative methods. It should be noted that quantitative method was supportive. The views presented in the study are mainly based on the information obtained from qualitative methods.

The study was anonymous. The survey was sent to the students in the educational electronic database (http://emis.openuni.edu.ge). Bachelor and Master students of the Schools of Law, Business and Social Sciences participated in the study. Data collection lasted for 3 weeks. The total number of participants was 498.

The key issues of the research were"

Which thinking ability is critical thinking and why should it be taught?

How is critical thinking understood in Georgian reality (in general and on the example of TOU)

\footnotetext{
1 https://education.illinois.edu/docs/default-source/faculty-documents/robert ennis/thenatureofcriticalthinking_51711_000.pdf?sfvrsn=7bb51288_2
} 
What are the effective methods of teaching critical thinking?

What kind of person can be considered critical thinker?

The main components of the survey were:

- to study of opinion and attitude of students interested in critical thinking.

- to evaluate critical thinking at the present stage

\section{Research Results and Findings}

From 498 students who were involved in the survey, the majority were between the age of 19 to $24(87.7 \%)$.

The first question was intended to check students' general perception of critical thinking.

Figure 1

\section{What Kind of ability is critical thinking?}

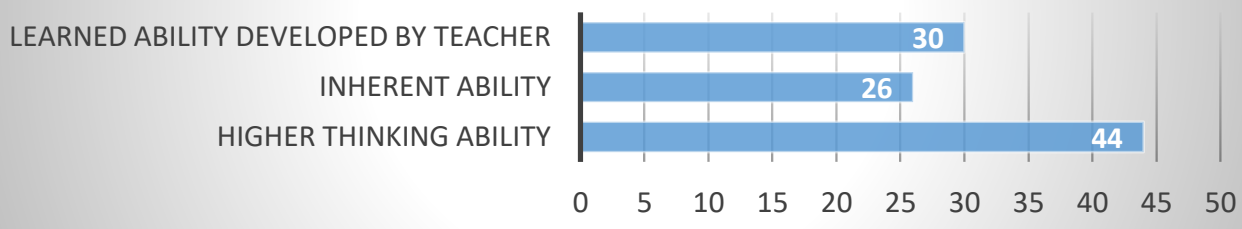

With the next question (figure 2), we wanted to find out if students considered critical thinking as something negative, as it is often mistakenly defined by some people. They could mark two answers. The results were quite pleasant as our students' awareness regarding critical thinking is quite correct.

Figure 2

\section{What does critical thinking mean?}

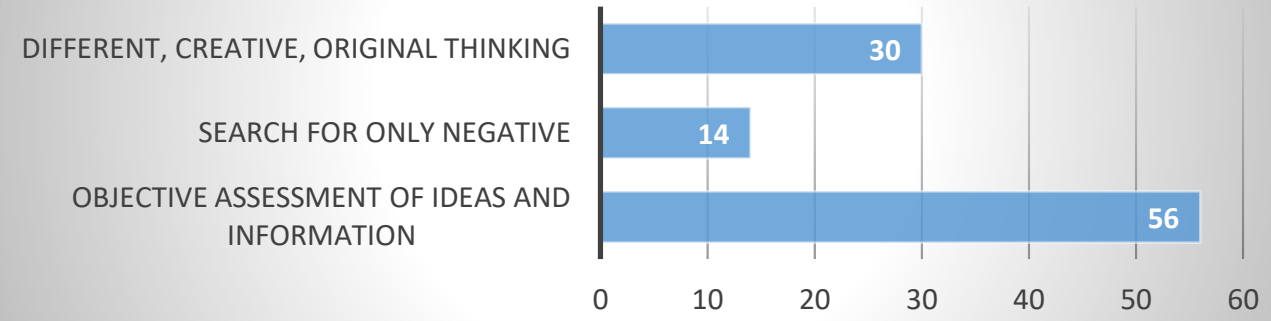

Figure 3 demonstrates how our students see the necessity of acquiring critical thinking skill. Majority of them consider critical thinking crucial while developing their knowledge. 
Figure 3

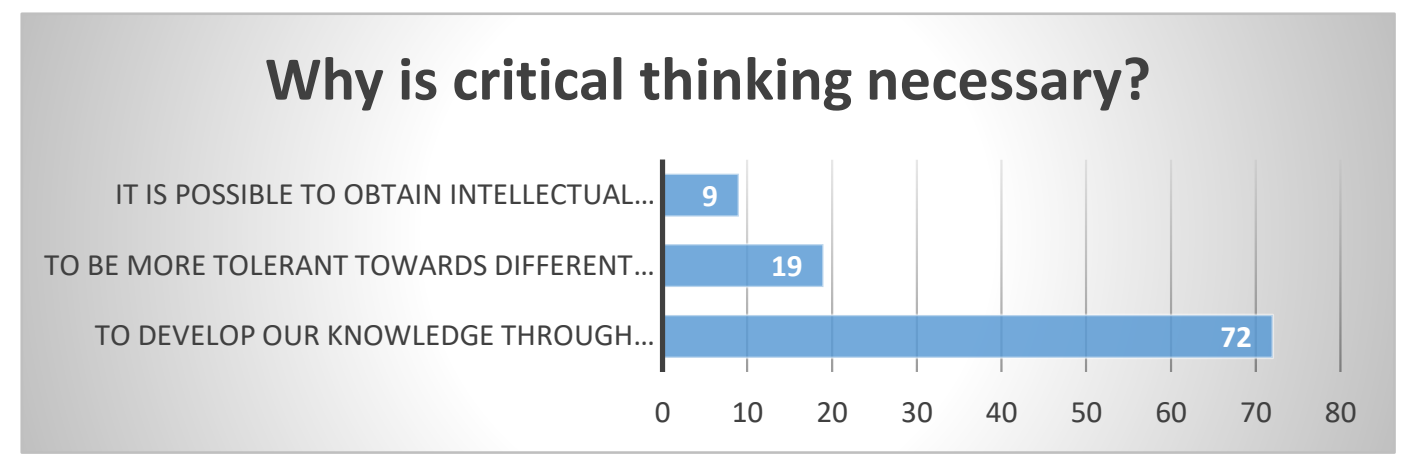

According to students' answers, critical thinking is a skill, which should be taught by higher education institutions. Unfortunately, we can not agree with them as we are sure that preschool is the right place to introduce critical thinking methods.

Figure 4

\section{Which level of education is appropriate for teaching critical thinking skills?}

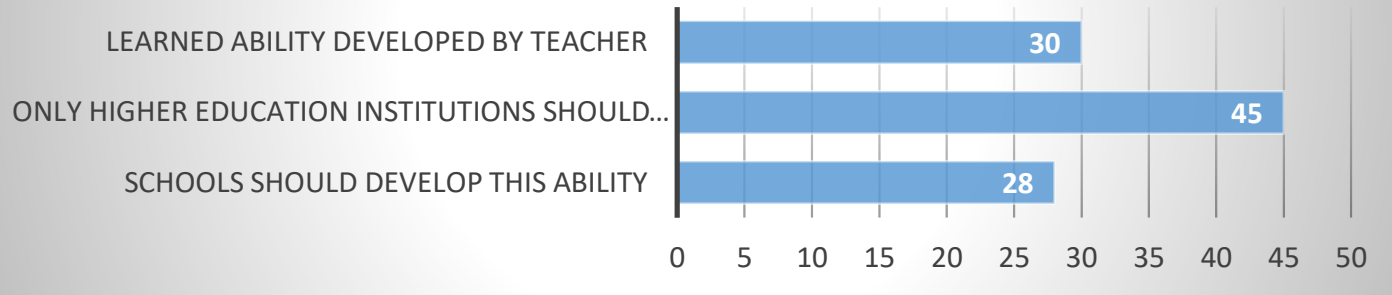

As we see from Figure 5 professors encourage students to express ideas and opinions frequently, but there are some barriers hindering students. There are several reasons: lack of confidence, knowledge, courage, ability. It is noteworthy that students avoid issues which cause controversy, debate, opposition from peers. 


\section{During seminars are you given chance to express your own, independent...}

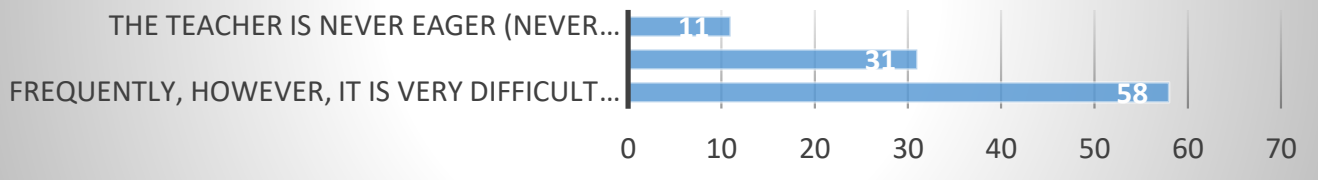

Figure5

For creating a system which promotes critical thinking and facilitates the development of this skill all factors are equally important. It is essential to teach critical thinking, not as a separate subject, but it should be incorporated in every course.

Figure 6

\section{How shall we create critically thinking "educational system"?}

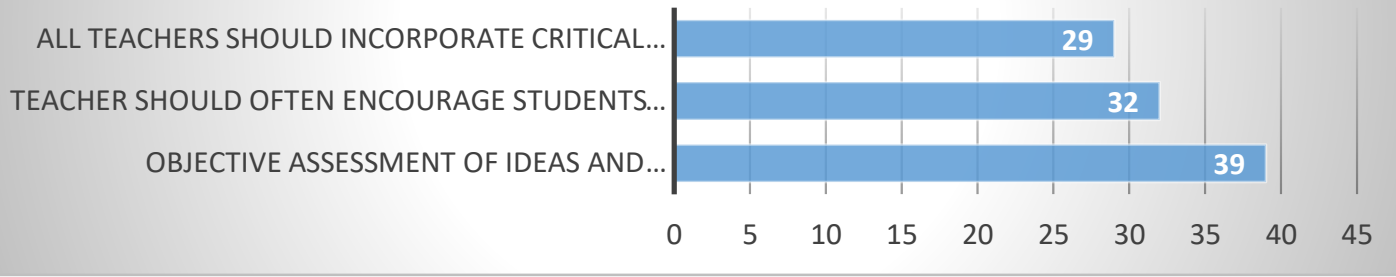

\section{Conclusions}

Critical thinking is correct thinking to obtain correct knowledge about the world. In other words, it can be described as reasonable, reflective, responsible, and skillful thinking that is focused on deciding what to believe or do. People who think critically ask appropriate questions, obtain relevant information, efficiently and creatively sort through this information, make logical judgments, reliable and trustworthy conclusions about the world that enable one to live and act successfully in it.

Critical thinking is higher-level thinking, enabling a person to responsibly judge about world issues. It enables us to be a responsible citizen who contributes to society. Children are not born with the power to think critically, nor do they develop this ability naturally beyond. It is a learned ability that must be taught and it must be taught by trained and knowledgeable teachers.

\section{References:}

[1] Bailin, Sharon (1995). "Is critical thinking biased? Clarifications and implications." Educational Theory, vol. 45 no. 2 
[2] Bean, J .: Engaging Ideas: Professor's Guide to Integrating Writing, Critical Thinking, and Active Learning in the Classroom. San Francisco, Jossey-Bass 1996.

[3] Brookfield, S. D. (2012). Teaching for critical thinking: Tools and techniques to help students question their assumptions. San Francisco: Jossey-Bass.

[4] Dewey, J.(1909). How we think. London: Heath.

[5] Ennis, R. H.(1997). Incorporating critical thinking in the curriculum: An introduction to some basic issues. Inquiry: Critical thinking across the disciplines, 16. http://www.criticalthinking.net/IncorporatingCriticalThinkingInTheCurriculum.pdf

[6] Halpern, D. F. (2014). Thought and Knowledge: An Introduction to Critical Thinking (5th Edition). NY: Psychology Press.

[7] Johnson, RH: Some Observations about Teaching Critical Thinking. CT News, Critical Thinking Project, California State University, Sacrement. Roč. 4, No. 1, September-October, 1985.

[8] Klooster, D.(2001). What is Critical Thinking? Thinking Classroom/Peremena Spring 2001 (4)

[9] Kuhn, D. (1999). A developmental model of critical thinking. Educational Researcher, 28(2).

[10] Lipman, M. (2003). Thinking in education. New York: Cambridge University Press.

[11] Norris, Stephen P. (1992). The Generalizability of Critical Thinking (New York: Teachers College Press).

[12] Meyers, C .: Teaching Students to Think Critically: A Guide for Faculty in All Disciplines. San Francisco, JosseyBass 1986.

[13] Paul, Richard (1990). Critical Thinking: What Every Person Needs to Survive in a Rapidly Changing World (Rohnert Park, CA: Center for Critical Thinking and Moral Critique).

[14] Talaska, Richard A. (1992). Critical Reasoning in Contemporary Culture (Albany: SUNY Press).

[15] file:///C:/Users/use/Desktop/khatia+rusa+sopo/dp_sukenikova\%20-\%20klooster.pdf

[16] https://education.illinois.edu/docs/default-source/faculty-documents/robertennis/thenatureofcriticalthinking_51711_000.pdf?sfvrsn=7bb51288_2

[17] http://www.criticalthinkinginternational.org/

[18] https://sites.google.com/site/dianehalperncmc/home/research/halpern-critical-thinking-assessment 